general neurasthenia, and hence the treatment must be chiefly directed to the improvement of the condition of the patient's nervous system. In many cases it is associated with a general toxic condition such as is met with in constipation and dyspepsia and is probably due to defective nutrition of the retina owing to the toxic condition of the blood. In such cases, also, the treatment of the general health of the patient is all important and only when the patient's general health is bronght into a satisfactory condition will the retinal asthenopia disappear. Local treatment, such as rest, protection from bright light, and the use of ocular analgesics, such as holocaine and dionine, will give a certain measure of relief to the sufferings of the patient, but the removal of the asthenopia and the ability of the patient to use the eyes will only be accomplished by improvement in the general health of the patient and until this is effected the asthenopia will continue in spite of all local measures. The removal of the varied symptoms due to muscular eye strain will be successfully accomplished by the prescription of suitable glasses and by intelligent care in the ure of the eyes.

In many cases it will ke necessary for the patient to wear glasses constantly even apart from near work. This is the part of the treatment which it is often very difficult to get the patient to comply with and yet is often most essential for the removal of the symptoms of eye strain. A patient with hypermetropia or astigmatism is constantly using his accommodation even for distance, hence the eye rapidly gets into a fatigued condition and is unable to accompl'sh without discomfort the further effort required for close work. If the hypermetropia or astigmatism be corrected and the lens constantly worn the eye is now in a position of rest and may be able to respond to the increased effort required by near work. The patient must be made clearly to understand that the distance glass is to be worn constantly, not in order to make him see more clearly but in order to make him see with less effort and keep the eye in a position of rest. In a very large number of cases of eye strain this is the all important point in their succes-ful treatment and it is the point of the treatment which it is very often difficult to get the patient to adopt owing to the irrational prejudice in many minds against the constant wearing of glasses. Further assistance may be given if necessary by prescribing a special glass for near work and this $I$ do in a large number of cases, even in young people, who are using their eyes much for near work. The object to be aimed at in cases of -eye strain is to enable the patient to exercise the functions of vision with a minimum of exertion on the part of the eye.

Another part of the treatment quite as important as the wearing of glasses is intelligent care in the use of the eyes. I saw a patient a short time ago who was suffering from eye strain and who informed me that he was using his eyes for fine work for nearly 17 hours a day. There was no error of refraction whatever and the discomforts complained of by the patient were simply due to overtaxing the eyes-a con dition which no spectacles could ameliorate. People must be taught that the eye can be overwrought and that it is only capable of accomplishing a certain amount of near work with comfort to the individual. I have often given people great relief by curtailing the amount of near work or by advising them to take periods of rest and not to work the eye too continuously for long periods of time.

Great benefit may also be derived by being careful to avoid exerting the eyes excessively in looking at very minute objects. Ladies suffering from eye strain I always advise for a time to abandon any fine sewing and rather to take to knitting, which being largely accomplished by the sense of touch does not throw anything like the same strain upon the eyes. Those who are fond of reading I specially request to use only books which have large and clear type I often refer my patients to Lord Rosebery's " Napoleon," published by Humphreys of London, as a model of what a printed book ought to be, dull paper, thick black letters of good size, with ample room between the individual letters and the lines. A book printed in this way means a minimum of exertion to the eye. In the case of children this is of very special importance. Much greater attention has been given to this of recent years by the puhlishers of children's books. The series of school books published by Messrs. William Collins, Sons, and Co., "Collins' Clear Type Press," deserve special commendation as in the clearness and blackness of the type, the size of the letters, and the large spacing they form models of what such books ought to be and confer a real benefic on the rising generation of school children. Care with regard to proper illumination is also of importance in cases of eye strain. The light should be good and not too intense. The greatest care should be exercised that whilst the book or object looked at is all illuminated the eyes themselves should be in the shadow and not exposed to the direct rays of light. Hence the light should be coming from a source behind, at the side, or above. The source of light should never be in front, as the rays of light entering the eyes directly fatigue the retina and so lead to eye strain. I have seen children suffer a great deal with their eyes from being placed at school with their faces to a large window all day long instead of with their backs to it. When the position of the lighting was altered their symptoms disappeared.

In the treatment of eye strain it is therefore important to impress on the patient that more is required than the prescription of suitable glasses. The patient must be instructed to use his eyes in an intelligent way so as to throw a minimum of strain upon them and allow the function of vision to be exercised under the most favourable conditions. Attention must be given to the length of time the eyes are used for near work, to the size of the objects looked at, and to proper illumination. The intelligent coöperation of the patient is necessary in such cases to bring about a satisfactory result. Any local affections of the lids, the passages, or of the eye itself of course require careful treatment. A patient will not be able to use his eyes with comfort until all pathological conditions of the eye itself, of the lids, and the tear passages have been removed.

Glasgow.

\section{THE ORIGIN OF CHOANAL POLYPI.}

\section{BY GUSTAV KILLIAN, M.D.,}

PROFESSOR OF LARYNGOLOGY AND RHINOLOGY, UNIVERSITY OF FREIBURG IN BREISGAU.

AMONG nasal polypi the so-called choanal or benign nasopharyngeal polypi occupy a special place. This has already been emphasised by Moldenhauer and lately Gerber has confirmed it. My own experience, which extends over 22 cases, also coincides. Choanal polypi are usually unilateral and solitary. They have a peculiar pear-shaped form, the broad end lying in the naso-pharynx whilst the stalk extends some distance into the nose. In the thick part of the polypus there is usually a large cystic space. This may be prolonged far into the stalk or the stalk may consist of nothing more than the thin wall of a particular cyst, which may, of course, be ruptured in the process of extraction. Once I observed a distinct groove of constriction where the pear-shaped part of the polypus pusses into the stalk. Choanal polypi are characterised by the considerable size which they may attain. They are subject occasionally to inflammatory changes (according to my experience in 14 per cent. of the cases) which may terminate in partial or total gangrene. spontaneous rupture of the cystic spaces in the polypi and spontaneous expulsion of the whole mass have been observed.

In microscopical structure these polypi hardly differ from the ordinary nasal polypi. The surface of the part lying in the naso pharynx is usually pretty firm, of a whitish appear. ance, with flattened epithelial covering. The tissue of the tumour is composed of loose cdematous connective tissue. The cysts take their origin from large collections within the trabeculæ and are therefore not clothed with epithelium. If the polyp inflames it becomes very red, swollen, and covered with foetid purulent mucus and at points with false membrane. The tissue contains hæmorrhagic extravasations and is infiltrated freely with round cells.

From the point of view of treatment choanal polypi are very favourable. They may be laid hold of in various ways and readily torn out on account of their slender stalk. In the process the cyst in the body of the polyp, as a rule, bursts and I have observed immediately after the extraction, more particularly if the head be bent forward, a large quantity of sanguineous, serous fluid come away. In the majority of cases the polypi do not recur. The examination of the maxillary antrum shows in a series of cases a chronic inflammation of slight degree, with simple mucus, rarely puralent secretion.

Whoever glances through the literature of these peculiar growths will be struck by the fact that the views upon the 
origin of choanal polypi are extraordinarily varied and indefinite. Usually the region of the choans is regarded as the point of origin. A number of observers have stated that they come from the middle meatus but without committing themselves definitely to the exact point of origin. Moldenhaver thinks that they usually originate laterally in the upper part of the posterior end of the middle turbinal.

$\mathrm{My}$ own interest in the question of the origin of the polypi described above took shape when two years ago I sought in vain, assisted by all the diagnostic aids recently placed at our disposal, for the origin of the polypus in a typical case. Even by means of median rhinoscopy, which has done me most excellent service in the examination of the nasil fossæ, no spot was found which could be regarded as the base of the polyp in question. I found in this case the accessory opening of the maxillary antrum unuivally large and came to the conclusion that the polyp might have bad its root within that cavity. The close observation of seven more cases enabled me to regard this as a definitely established fact of general application.

Anyone who wishes to convince himself of this should, in the first place, make as careful an examination as possible before the removal of the polypus, which for the most part is carried ont in a hurried manner. The long nasal speculum should be introduced into the middle meatus, previously well cocainised, and the middle turbinal firmly pressed towards the septum. After cleansing the field of view the stalk of the polyp will be seen to disappear laterally behind the region of the uncinate process. By means of a nasal probe bent forwards at right angles the observer may succeed by following the stalk in entering the maxillary sinus through an accessory antral opening. By drawing the hook of the probe against the anterior edge of this opening, laying it against the posterior edge, and following the upper and lower margins, the great width of the accessory opening may be determined with ease in these cases. This width can be definitely measured by marking the relative pasition of the anterior and posterior margin of the ostium to the external nasal entrance. I have found it to be from 1.7 to 2.2 centimetres.

For further observations on the antral origin of the polypi in question I r commend their extraction to be carried out with the cold snare. The wire loop is passed over the body of the polyp, slowly tightened, and laid close up to the spot where the stalk comes out of the antrum. The process of snaring is carefully done so that the stalk is not cut through. Then the polypus is torn out. By such a procedure the length of that part of the stalk lying inside the antral cavity may be determined with exactitude. I have found it from three to four centimetres long. It may be almost as long as the rest of the polyp. In the extraction of the mass a certain resi-tance is felt. As a rule, in the first place the cyst in the naso-pharyngeal portion of the polyp ruptures and discharges a large quantity of fluid. Further traction tears the polyp away suddenly.

I explain the resistance so clearly felt during the extraction in this way, that the portion lying inside the antrum is not by any means so thin as it appears after extraction but is swollen ap by cystic fluid inside that cavity, in the same way as the body of the polyp. In extraction this thick intramaxillary part is pulled through the (in spite of its ahsolute width, relatively narrow ostium into the nose. This, of course, crushes the intramaxillary portion and its cyst ruptures. The cystic fluid falls into the empty antrum. The stalk is found to consist of a collapsed cyst wall. The fluid left in the antrum comes away later, especially when the head is held in a particular position, as already mentioned. It is obvious that the groove of constriction which I have observed in the stalk of the polyp is caused by the edge of the accessory o-tium. Choanal polypi must in reality all have the form of a constricted sac, of which the one half is in the antrum and the other in the nose and nasopharynx. We distinguish, therefore, a maxillary from a naso pharyngeal part.

In further support of the maxillary origin of the choanal polypus it may be stated that on one oncasion I saw the torn stalk project out of the accessory antral opering. In another case the reinains of the plypus stalk within the antrum could be seen by means of a small mirror introduced into the middle meatus. Such cases would form suitable objects for investigation with the antroscope. It is to be hoped that with this in-trument still more definite conclusions upon the actual $p$ int of origin within the antrum may be obtained.

The fact that the choanal polypi originate within the antrum of Highmore explains their general and especially also their clinical behaviour. At first there is apparently a simple antral polypus. Part of this, occasionally as a result of blowing the nose, finds its way through the wide accessory opening into the middle meatus. A parallel to this is the observation that by inflation and irrigation of the antram through the accessory ostium a polypus is occasionally driven out of the cavity into the nose as mentioned by Grünwald and Hajek. If a slender antral polyp gets caught in the ostium and fixed there we have the conditions present for its further development into a regular choanal polyp. In the first place a high degree of congestion must take place in the nasal portion. Hence the polyp grows pretty rapidly In the posterior half of the middle meatus it finds but little room and here the slender part of its body is formed. When it reaches the naso-pharynx it may without hindrance attain considerable size, but the circulatory con. ditions are already so hampered that it tends less to new tissue formation than to collections of fluid within the meshes of the tissue, so that the formation of large cysts in the naso-pharyngeal portion is the result. It can scarcely be doubted that the growing stalk of the polypus presses in its turn upon the walls of the accessory ostium and widens this entrance. Under certain conditions, perhaps as the result of an acute catarrh, marked constriction of the polypus stalk within the accessory opening supervenes. As a consequence we have the appearances of inflammation, and redness, swelling, blood extravasations, \&c., which may proceed to partial and total gangrene and even to spontaneous expulsion of the naso pharyngeal portion.

The history of the development of the solitary choanal polypus leads back to the origin of antral polypi. That these owe their origin to inflammation of the antral mucous membrane is generally admitted. A case recently observed by me is especially instructive in this connexion and is of all the more interest here because it demonstrates the entire developmental history of a choanal polypus. I observed in this case two years ago a simple acute maxillary sinusitus with citron-yellow, glassy, mucous secretion, which rapidly healed after several irrigations. Examination showed a year later nothing particular in the nose and middle meatus. A short time ago, after the lapse of about a year, the patient in question came to me with a typical choanal polypus which had its root in the antrum formerly affected.

It may be mentioned that all stages from the antral polypus to the fully formed naso-pharyngeal polypus may occasion. ally be observed. Once I saw two polypi project out of the accessory ostium. In the numerous cases in which the nasal cavities are filled with polypi instances often come under notice which are like typical choanal polypi. As a curiosity I may mention a case in which a solitary naso-maxillary polypus had an angiomatous structure.

Changes analogous to those in the region of the accessory antral opening may also, of course, be observed about the opening of other accessory sinuses, and polypi which have developed within these sinuses may protrude through the openings into the nasal cavities and there take on further growth. There is no doubt that a polypus springing from a posterior ethmoidal cell or the sphenoidal sinus may in rare cases be transformed into a choaval polypus which can be distinguished from the majority of the abovedescribed maxillary choanal polypi only by the most careful examination of the origin, especially before extraction. Zuckerkandl has given pictures of such cases. We find in his book illustrations of polypi which had grown with long stalks out of the antrum through the accessory ostium into the nose. In the literature of the subject I find the interesting statement that Palfyn (1753) had already observed such a case.

Freiburg.

Medical Magistrate.-Mr. Robert Roxburgh, M.B. Edin., F R.C.S. Edin., of Weston-super-Mare, has been placed on the commission of the peace for the county of Somerset.

Somerset County Council and the Training OF MIDWIVES.-At a meeting of the Somerset county council held at Taunton it was decided to make a special grant of $£ 150$ to the Somerset County Nursing Association for the training of six nurse-midwives who would-be willing to work for the assosiation in the county of Somerset for a term of at least three jears after the conclusion of their training. 